\title{
Photobiomodulation in speech-language-hearing therapy: a profile of professional practice and the level of information of Brazilian speech-language- hearing therapists
}

\author{
Paula Rayana Batista Correia ${ }^{1}$ \\ https://orcid.org/0000-0002-7683-2765 \\ Julyane Feitoza Coêlho ${ }^{1}$ \\ https://orcid.org/0000-0003-3632-2653 \\ Maria Louize Justino Freire ${ }^{1}$ \\ https://orcid.org/0000-0001-6190-1310 \\ Larissa Nadjara Alves Almeida ${ }^{1}$ \\ https://orcid.org/0000-0002-6818-3398 \\ Leandro de Araújo Pernambuco' \\ https://orcid.org/0000-0001-6246-9769 \\ Giorvan Ânderson dos Santos Alves ${ }^{1}$ \\ https://orcid.org/0000-0003-1619-0139
}

Universidade Federal da Paraíba - UFPB, João Pessoa, Paraíba, Brasil.

Conflict of interests: Nonexistent

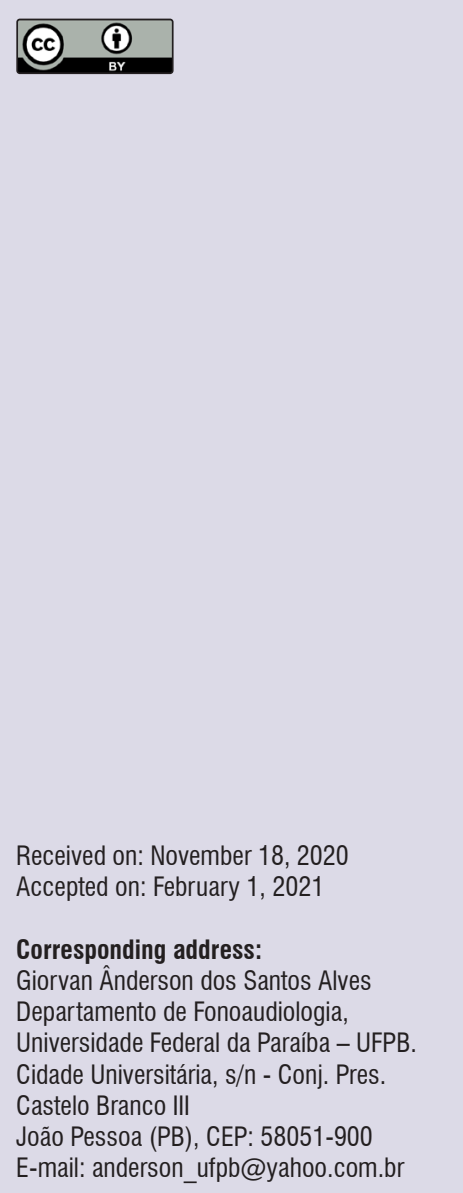

\section{ABSTRACT}

Purpose: to know the profile of Brazilian speech-language-hearing (SLH) therapists and their level of information on the use of low-level laser photobiomodulation.

Methods: an observational, cross-sectional, quantitative study conducted with a self-administered online questionnaire related to the professional education, work, and knowledge of SLH therapists on low-level laser photobiomodulation. Two hundred sixty-one speech-language-hearing therapists of both sexes participated in the research. The data were analyzed with descriptive and inferential statistics.

Results: the speech-language-hearing therapists had graduated predominantly 10 to 20 years before, their highest degree was mainly specialization, and most of them worked in the fields of oral-motor functions, dysphagia, voice, language, and audiology. Most of them knew photobiomodulation and its use in SLH therapists; also, they agreed on using a low-level laser as a therapeutic resource. Even so, most did not use it in clinical practice, although those who did, reported greater patient adherence. Statistical significance was verified for the association between laser use and access to resolution number 541 of the Federal Speech-Language-Hearing Council, time in the profession, main specialization, and required qualification.

Conclusion: the participating speech-language-hearing therapists showed knowledge on low-level laser photobiomodulation and its applicability. However, most of these professionals did not use the resource yet.

Keywords: Speech, Language and Hearing Sciences; Speech Therapy; Lasers; Laser Therapy; Low-Level Light Therapy 


\section{INTRODUCTION}

Speech-language-hearing (SLH) pathology is a field of health encompassing a broad range of training, education, research, prevention, assessment, diagnosis, development, improvement, and (re)habilitation of the aspects of human communication and orofacial functions, from childhood to old age. The practice of professionals who work in this field has been changing over the years, while the research to better direct the evidence-based practice has been increasing.

Health-related technology has been growing steadily, with noticeable benefits from implementing the new resources and therapeutic techniques, leading to a more effective therapy ${ }^{1}$. In this innovative scenario, SLH therapy has been improving its use of technologies associated with conventional therapy. One of such technologies is photobiomodulation - a therapeutic technique using light, which acts upon biological activity causing physiological changes ${ }^{2,3}$. This technique uses, among other resources, low-level laser (LLL), which can be helpful in SLH therapy when associated with practices traditionally used in the field ${ }^{4,5}$.

In March 2019, the use of this resource in SLH practices was regulated by the Brazilian Federal SLH Council (Conselho Federal de Fonoaudiologia - CFFa) with Resolution no. $541^{6}$. LLL is a noninvasive resource used in photobiomodulation therapy that consists of irradiating light on a given place ${ }^{7,8}$. This resource uses electromagnetic radiation with visible and near-infrared wavelengths, of which the most used wavelengths in SLH photobiomodulation are the red and the infrared ${ }^{9}$.

LLL has been increasingly used for being a relatively safe technique, as it does not expose the patient to predictable risks or damages. However, despite being an easy-to-use procedure, it requires a qualified professional for the results to be satisfactory, based on knowledge of its intervention principles. The desired therapeutic effects need to be established, as well as the correct dosage, the administration time, the irradiation points, and the energy flow mode, whether pulsatile or continuous ${ }^{7,9,10}$.

The photobiomodulation can benefit various SLH treatments, with satisfactory results especially in oralmotor functions and dysphagia ${ }^{4,11}$. Although most of the research and interventions occur in these fields, the audiology specialists have also been investing in LLL as an intervention resource, as seen in research on the rehabilitation of patients with tinnitus ${ }^{12,13}$.
Given the scarcity of research in the scientific literature involving the use of photobiomodulation in SLH therapy and the recently issued CFFa resolution, this study aimed to know the profile of Brazilian SLH therapists and their level of acquaintance with the use of the LLL technique.

\section{METHODS}

The research project was previously submitted to the evaluation of the Human Research Ethics Committee of the Department of Health Sciences at the Federal University of Paraíba (Universidade Federal da Paraíba - UFPB), PB, Brazil, being approved with evaluation report number 4.103.029. All the volunteers of the study had access to the informed consent form and agreed to participate.

This is an observational, cross-sectional, quantitative study. A total of $261 \mathrm{SLH}$ therapists of both sexes participated in the study. They were selected by convenience, with the eligibility criteria of being a professional with an SLH bachelor's degree, working in Brazil.

The research was carried out with an online questionnaire disseminated via social media and message applications. Every Friday for 4 weeks, a pamphlet of the research was shared along with a link to Google Forms for the volunteers to access the informed consent form and the questionnaire of the study.

The data, consisting of the answers of the volunteers to the adapted questionnaire, were collected between June and July 2020. It was based on a previous study ${ }^{14}$ and had 34 questions - seven open-ended and 27 closed-ended questions - encompassing the SLH therapist's profile, professional education, work, and knowledge of photobiomodulation, as presented in the Appendix.

The data were organized and categorized in Microsoft Excel spreadsheets for data analysis. Descriptive statistical analysis was conducted with measures of frequency and standard deviation. Inferential statistics used the Pearson chi-square association test. The data were analyzed with the Statistical Package for the Social Sciences (SPSS), trial version 22. Values lower than $1 \%$ were considered significant.

\section{RESULTS}

The research was intended for Brazilian SLH therapists, and it counted with the participation of 
professionals from various regions. However, the states with the highest number of participants were Paraíba (28\%), São Paulo (21.5\%), Pernambuco (8.8\%), Minas Gerais (8\%), and Rio de Janeiro (6.1\%).

The sample's mean age was 38.02 years (SD = 11.11). The highest education degree of most of the professionals was specialization, followed by doctor's degree, master's student, master's degree, specialization student, and bachelor's degree, as shown in Figure 1. Most of the professionals had been working in the field for 10 to 20 years (33.71\%), followed by 1 to 5 years (25.67\%), 21 years or more (24.9\%), 5 to 10 years (8.42\%), and up to 1 year (7.27\%).

\section{HIGHEST EDUCATION LEVEL}

\section{- BACHELOR'S DEGREE}

- MASTER'S STUDENT - DOCTOR'S DEGREE

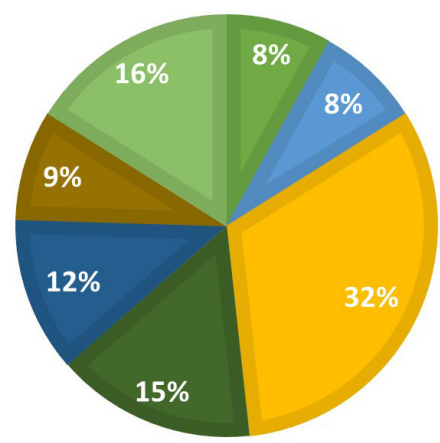

Caption: $\mathrm{n}=261$

Figure 1. Distribution of the participating speech-language-hearing therapists according to their highest education level

Of the participating professionals, $29.5 \%$ are professors, teaching in undergraduate $(7.3 \%)$ or postgraduate programs $(10.3 \%)$, or both $(11.9 \%)$. Also, some of them $(6.5 \%)$ are professors whose content approached photobiomodulation.

The main specializations pointed out by the participants are shown in Figure 2. As for the main fields of work (of which the professionals could choose more than one option), the participants listed oral-motor functions $(62.1 \%)$, dysphagia (54.8\%), voice $(46.4 \%)$, language (45.6\%), and audiology (18.8\%). The professionals were mainly working at clinics/offices $(69.3 \%)$, home care (36.4\%), and hospitals (28\%). 


\section{MAIN SPECIALIZATION}

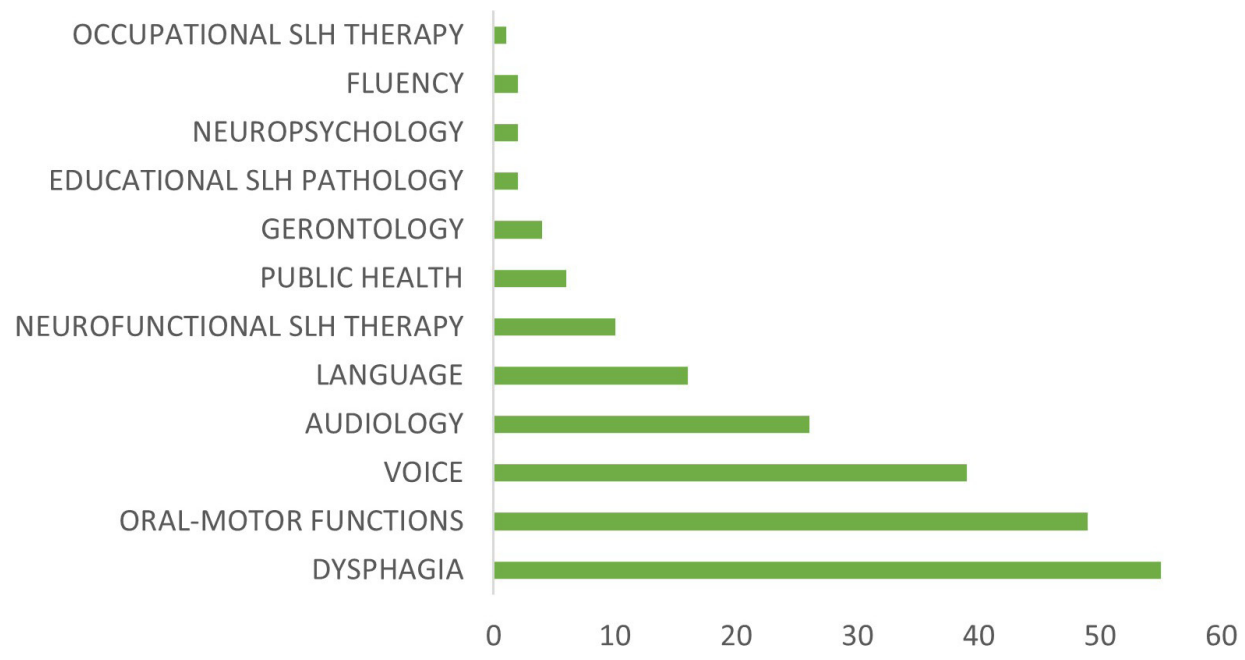

Caption: Absolute frequency of Brazilian speech-language-hearing therapists according to their main specialization. $\mathrm{n}=261$. SLH: speech-language-hearing

Figure 2. Main field of specialization of the participating speech-language-hearing therapists

Most of the SLH therapists stated they knew photobiomodulation (92.3\%) and its use in SLH therapy (89.7\%). Of the participants, $67.4 \%$ had accessed the CFFa recommendations for the use of LLL by SLH therapists. Only $24.9 \%$ had researched and published about photobiomodulation, mostly on the fields of oralmotor functions (12.9\%), dysphagia (9.6\%), and voice (6.5\%).

Of the professionals that answered the questionnaire, $56.3 \%$ had already studied or been qualified to work with photobiomodulation in SLH therapy or health care. The mean time studying the technique was 2.44 years $(S D=1.94)$, with a mean course load of 62.01 hours (SD $=170.17)-$ a minimum of 8 and a maximum of 500 hours. Also, $79.82 \%$ of the SLH therapists who had not yet been qualified to use photobiomodulation indicated they were interested in it.

It was identified that $84.7 \%$ of the participants had not been introduced to the technique during their undergraduate program, neither had $82.81 \%$ at any moment in their postgraduation. However, $67.4 \%$ had already accessed some bibliography related to photobiomodulation in SLH therapy or health care.

Of those researched, $53.6 \%$ usually do not use LLL in clinical practice. Those who use it, have done so for 2.41 years $(S D=1.90)$. The impact of therapeutic LLL use on the patients' adherence was measured on a scale from 0 to 5 , resulting in a mean of 4.25 points $(S D=0.96)$. Concerning the frequency of everyday use of the resource, using the same scale, the mean was $3.77(S D=1.07)$. The three main clinical uses of the resource pointed out by the SLH therapists were in cases of dysphagia (33.05\%), facial palsy interventions $(22.31 \%)$, and saliva control (sialorrhea/hypersalivation) in $14.87 \%$ of the answers. Besides these, other highlighted uses include temporomandibular joint disorder (TMD) (14.04\%) and muscle performance (9.09\%).

Most of the 121 professionals who use laser do so at the beginning of the therapy. Also, most of them (55\%) did not answer the main therapeutic effects in LLL intervention. The answers that were given are distributed as shown in Figure 3. 


\section{MAIN THERAPEUTIC EFFECTS}

\section{ANALGESIA \\ REGENERATION \\ BIOMODULATION}

aNTI-INFLAMMATORY — NOT REPORTED

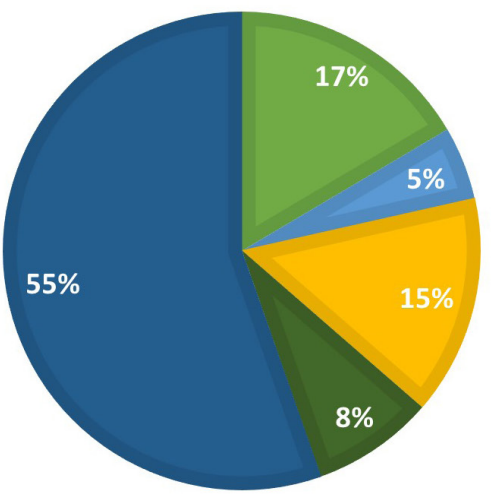

Caption: $n=121$

Figure 3. Measures of the frequency of the main photobiomodulation therapeutic effects

Of all the participants, $57.9 \%$ have access to an LLL device, most of whom have their private one (44.4\%). Also, most of them agreed with using LLL as an SLH therapy resource (98.5\%). Likewise, most of the therapists are familiar with the biosafety rules for using the device (69\%).
Of the professionals who used laser in clinical practice, $94.2 \%$ had access to the CFFa recommendations. Moreover, there is a statistically significant association ( $p<0.01$ ) between using LLL and having access to the recommendations - i.e., more professionals who use laser had access to them (Table 1).

Table 1. Association between laser use in clinical practice and access to the recommendations of the Federal Speech-Language-Hearing Council

\begin{tabular}{ccccc}
\hline $\begin{array}{c}\text { Laser use in clinical } \\
\text { practice }\end{array}$ & $\begin{array}{c}\text { Did not have access to } \\
\text { the recommendations }\end{array}$ & $\begin{array}{c}\text { Had access to the } \\
\text { recommendations }\end{array}$ & \% of the total & P-value \\
\hline Laser not used & $78(55.7 \%)$ & $62(44.3 \%)$ & $140(53.6 \%)$ & \\
Laser used & $7(5.8 \%)$ & $114(94.2 \%)$ & $121(46.4 \%)$ & $p=0.0001^{*}$ \\
$\%$ of the total & $85(32.6 \%)$ & $176(67.4 \%)$ & $261(100 \%)$ & \\
\hline
\end{tabular}

Pearson's chi-square test, $p<0.01$ *

Similarly, almost all (99.2\%) professionals who use a laser in clinical practice have studied or been qualified to work with photobiomodulation in SLH therapy or health care $(p<0.01)$, as presented in Table 2.

Table 2. Association between laser use in clinical practice and studies/qualification in photobiomodulation

\begin{tabular}{ccccc}
\hline $\begin{array}{c}\text { Laser use in clinical } \\
\text { practice }\end{array}$ & $\begin{array}{c}\text { Did not study/qualify in } \\
\text { photobiomodulation }\end{array}$ & $\begin{array}{c}\text { Studied/qualified in } \\
\text { photobiomodulation }\end{array}$ & \% of the total & P-value \\
\hline Laser not used & $113(80.7 \%)$ & $27(19.3 \%)$ & $140(53.6 \%)$ & \\
Laser used & $1(0.8 \%)$ & $120(99.2 \%)$ & $121(46.4 \%)$ & $\mathrm{p}=0.0001^{*}$ \\
$\%$ of the total & $114(43.7 \%)$ & $147(56.3 \%)$ & $261(100 \%)$ & \\
\hline
\end{tabular}

Pearson chi-square test, $p<0.01^{*}$. 
A significant association $(p<0.01)$ was verified between the SLH therapist's main specialization and the use of laser in clinical practice. Most of the professionals whose main field of specialization is oral-motor functions, dysphagia, and voice use this resource in their practice, highlighting oral-motor functions, with $71.4 \%$ of such specialists using it. On the other hand, most of the professionals in audiology and language do not use LLL, as shown in Table 3.

Table 3. Association between the main specialization and laser use in clinical practice

\begin{tabular}{|c|c|c|c|c|}
\hline Main specialization & Laser not used & Laser used & $\%$ of the total & P-value \\
\hline Audiology & $17(65.4 \%)$ & $9(34.6 \%)$ & $26(10 \%)$ & \multirow{14}{*}{$p=0.0001 *$} \\
\hline Dysphagia & $24(43.6 \%)$ & $31(56.4 \%)$ & $55(21.1 \%)$ & \\
\hline Fluency & $2(100 \%)$ & $0(0 \%)$ & $2(0.8 \%)$ & \\
\hline $\begin{array}{c}\text { Occupational SLH } \\
\text { Therapy }\end{array}$ & $1(100 \%)$ & $0(0 \%)$ & $1(0.4 \%)$ & \\
\hline $\begin{array}{l}\text { Educational SLH } \\
\text { Pathology }\end{array}$ & $1(50 \%)$ & $1(50 \%)$ & $2(0.8 \%)$ & \\
\hline $\begin{array}{c}\text { Neurofunctional SLH } \\
\text { Therapy }\end{array}$ & $3(30 \%)$ & $7(70 \%)$ & $10(3.8 \%)$ & \\
\hline Gerontology & $1(25 \%)$ & $3(75 \%)$ & $4(1.5 \%)$ & \\
\hline Language & $12(75 \%)$ & $4(25 \%)$ & $16(6.1 \%)$ & \\
\hline Oral-Motor Functions & $14(28.6 \%)$ & 35 (71.4\%) & $49(18.8 \%)$ & \\
\hline Neuropsychology & $2(100 \%)$ & $0(0 \%)$ & $2(0.8 \%)$ & \\
\hline Public Health & $6(100 \%)$ & $0(0 \%)$ & $6(2.3 \%)$ & \\
\hline Voice & $17(43.6 \%)$ & $22(56.4 \%)$ & $39(14.9 \%)$ & \\
\hline $\begin{array}{l}\text { Do not have a } \\
\text { specialization }\end{array}$ & 40 (81.6\%) & $9(18.4 \%)$ & $49(18.7 \%)$ & \\
\hline$\%$ of the total & $140(53.6 \%)$ & $121(46.4 \%)$ & $261(100 \%)$ & \\
\hline
\end{tabular}

Caption: SLH: speech-language-hearing

Pearson chi-square test, $p<0.01^{*}$

A significant association $(p<0.01)$ was also observed between time in the profession and the use of laser in clinical practice (Table 4). Moreover, the proportion of use tended to increase as the time since graduation also progressed, and the predominance of use was verified in the professionals who had graduated 10 to 20 years before (59.1\%).

Table 4. Association between time in the profession and laser use in clinical practice

\begin{tabular}{ccccc}
\hline Time in the profession & Laser not used & Laser used & $\%$ of the total & P-value \\
\hline Up to 1 year & $16(84.2 \%)$ & $3(15.8 \%)$ & $19(7.3 \%)$ & \\
From 1 to 5 years & $51(76.1 \%)$ & $16(23.9 \%)$ & $67(25.7 \%)$ & \\
From 5 to 10 years & $10(45.5 \%)$ & $12(54.5 \%)$ & $22(8.4 \%)$ & $\mathrm{p}=0.0001^{*}$ \\
From 10 to 20 years & $36(40.9 \%)$ & $52(59.1 \%)$ & $88(33.7 \%)$ & \\
21 years or more & $27(41.5 \%)$ & $38(58.5 \%)$ & $65(24.9 \%)$ & \\
$\%$ of the total & $140(53.6 \%)$ & $121(46.4 \%)$ & $261(100 \%)$ & \\
\hline
\end{tabular}

Pearson chi-square test, $p<0.01^{*}$ 


\section{DISCUSSION}

This study was conducted to supply a lack of research in the field and point out the current LLL implementation status as an SLH therapeutic resource. Professionals from various Brazilian states participated, with a predominance of Northeastern and Southeastern states - where the studies in the field possibly come from, as they are not centralized in only one region.

The main specializations and fields of work of the participating professionals are dysphagia, oral-motor functions, and voice - which are also the SLH branches that present the most interest in laser and studies on it, exactly the fields whose professionals were most attracted to participate in the research.

Most of the participants were SLH specialists not working as professors, which may be related to the results found. Also, such aspects can mean that a greater number of clinical professionals are being attracted to photobiomodulation, perhaps showing interest in improving their professional practice.

Most of the participating SLH therapists had access to the CFFa recommendations on LLL use in the profession. It was recently approved, in March 2019, providing an official regulation for professionals in the field to use this resource. Such aspect may be associated with the little dissemination in the use of the technique and the still incipient amount of Brazilian research developed in this field. This specific standardization is expected to increase the use of laser, as it potentializes the SLH treatment when associated with other conventional therapies in the field. It is also expected that further research will be conducted to find evidence in SLH clinic ${ }^{14-16}$.

Most SLH professionals stated they knew photobiomodulation and the technique to use it in SLH therapy, besides having access to a private laser device. This is a positive finding, showing that, despite being a recent and innovative resource, it is accessible to these professionals and known by them. Nevertheless, most of them do not research or publish on photobiomodulation, resulting in a scarcity of Brazilian studies and publications on this topic. Of those who research, their studies are focused on oral-motor control - a tendency already observed in the national and international publications, which mainly involve themes related to this field. Therefore, as presented in a previous study ${ }^{14}$, what is found in the literature regarding LLL applied to SLH therapy is still incipient, calling for broadened scientific research.
Also, the results show that these professionals work mostly in assistance settings: clinics/offices, home care, and hospitals. These aspects may influence the inexpressive amount of research and publications, as a small part of the SLH therapists is in the universities and classrooms - which, along with the research institutes, are traditionally recognized as the main settings for national scientific production because they have activities, space, and resources made available with this purpose.

Most of the professionals have studied or been qualified to work with photobiomodulation in SLH therapy or health care. The CFFa recommendations state that LLL can only be used as a therapeutic resource by SLH therapists who have been adequately and specifically qualified - i.e., those who have a certificate of the course they have taken or a declaration of supervised practice ${ }^{6}$.

A relevant aspect is the photobiomodulation course load. There are currently no regulating parameters in this regard, and a great discrepancy was verified in the study between the minimum and maximum course load. It is worth highlighting that the more hours a professional has in quality theoretical-practical training, the greater their experience and mastery of the technique, making them more qualified to promote good practices in the use of the resource. Interestingly, it was verified that the participants' course load in photobiomodulation is quite close to the time of laser use in clinical practice; these professionals' qualification was likely acquired before using the resource.

Most of the participants of the study did not take classes on photobiomodulation at any moment during their education, which can be explained by the recent use of LLL in SLH therapy. On the other hand, most of them have already had access to some bibliography related to photobiomodulation, which reveals recent dissemination of studies on the theme, as well as a greater interest on the part of the professionals.

Considering that the use of new therapeutic resources can influence therapy, the professionals' evaluation of the impact of LLL was positive, demonstrating that the resource has a substantial effect on the patients' adherence. Certainly, using this resource promotes a greater adherence because of the early achievable benefits - such as analgesia in painful disorders, which can be already observed when it is used at the beginning of the therapy session, as evidenced in a study involving patients with TMD associating laser with conventional therapy ${ }^{5}$. 
Most of the professionals who use laser do so routinely. All the three main clinical uses pointed out by the participants have already been approached in previous studies, with positive responses. LLL proved to be a resource with a good approach to the treatment of dysphagia, especially in the treatment of patients with cancer ${ }^{3}$. Satisfactory results were also obtained in recovery from facial palsy, improving speech and chewing. It is effective to treat this pathology because of the capacity to change clinical and functional parameters in a short time ${ }^{17,18}$. Sialorrhea/hypersalivation was one of the LLL uses most indicated by the professionals who answered the questionnaire. Nevertheless, the scientific literature lacks studies proving its effectiveness, as only case studies were identified ${ }^{19}$.

Photobiomodulation is a resource that proposes immediate analgesic, anti-inflammatory, and regenerative action. Therefore, its use with LLL deserves an attentive look and greater exploration, given the benefits it may bring, as in the abovementioned cases ${ }^{7}$. In this study, more than half of the professionals who use laser did not mention its therapeutic effects, which indicates their unawareness regarding this essential aspect to be considered in the intervention. The other professionals, in their turn, listed analgesia and biomodulation as main therapeutic effects, corroborating the studies in this field ${ }^{5,20}$.

In this sense, a piece of research referred to analgesia as one of the main LLL therapeutic effects. The intervention resulted in comfort and eased pain for patients with $\mathrm{TMD}^{5,20}$. One of these papers presented significant results of the effects of biomodulation, helping increase mouth opening range, due to its action upon the cellular and tissue processes ${ }^{5}$. Regeneration is another one of the LLL effects, used to potentialize the intervention and accelerate the nerve recovery process in certain cases ${ }^{21}$.

Most of the professionals use this resource at the beginning of the therapy, which can be related to the therapeutic objectives proposed in the intervention, as the laser can bring immediate benefits and facilitate the rehabilitation process and the use of conventional SLH techniques, achieving more effective results.

A little more than half of the professionals researched do not use photobiomodulation in clinical practice. However, almost all of them agreed with the use of LLL as an SLH therapy resource. This may be a result of the advancements in such discussions, of the gains observed with the use of the technique, and its approval with the CFFa resolution. Establishing a specific regulation that instructs and ratifies the use of this resource by SLH therapists legitimates its use in professional practice. Moreover, it increases interest, with perspectives of greater professional adherence and dissemination of the technique in SLH therapy.

Another important aspect is that most of the participants know the biosafety rules to use the device. The therapist must be cautious regarding such rules involving them and the patient, wearing appropriate clothing and personal protective equipment, such as goggles to protect the eyes from the radiation, which can affect the retina?.

Considering only the professionals who use the laser in clinical practice, most of them had access to the CFFa recommendations, with a statistically significant association. This is an important aspect, as it demonstrates that they are properly informed of the official guidelines and recommendations regarding this part of their work.

Also, almost all the SLH therapists who used laser in clinical practice had studied or been qualified to work with photobiomodulation, which represents an interest in seeking such qualification, promoting good practices and adequate clinical procedures.

A significant association was also verified between the professionals' main specialization and laser use in clinical practice, with opposite tendencies, as professionals in the fields of oral-motor functions, dysphagia, and voice use laser clinically, whereas those in audiology and language do not use it routinely. This aspect may be related to each field's working profile and specificities.

Oral-motor functions is one of the SLH fields that deals with structural and functional aspects related to the stomatognathic system ${ }^{22}$. Studies related to this field identified satisfactory effects of laser associated with conventional therapy, $4,5,23$. In dysphagia, a specialty focused on difficulties/changes that occur in the swallowing process, international studies on the effect of photobiomodulation verified the effectiveness of laser in the treatment of changes associated with cancer therapy $3,11,24,25$.

As for the field of voice, the laser has been suggested to treat vocal fatigue, with positive results ${ }^{15}$. Despite the few studies relating laser and its effects to voice therapy, it can gain more visibility and adherence in therapeutic practices.

In audiology, the laser has been studied as an intervention resource for patients with tinnitus, providing positive results and reducing the discomfort caused by 
it. There is an incipient number of studies in this field; the existing ones are more specifically on patients with hearing loss and tinnitus ${ }^{12,13}$.

In the field of language, the studies are likewise focused on specific and restricted uses, such as the application of red and infrared photons on the scalp of patients with chronic aphasia. A study demonstrates that the resource can improve comprehension and local blood circulation in such cases ${ }^{26}$. However, its use is not much evidenced in the literature and the clinical use of transcranial photobiomodulation equipment has not yet been authorized in Brazil. Further research on the theme needs to be carried out to better understand the applicability of the resource and thus broaden its use.

An association was verified between time since graduation and laser use in clinical practice, as professionals who have been working in the field for 10 to 20 years are those who most use the laser. Such an unexpected aspect calls attention to the tendency of greater use of the resource on the part of professionals with greater experience - who commonly prefer traditional techniques, already consecrated by use. This result shows a trend of change in professional preferences and profiles, including good acceptability and use of laser in various sectors of the profession, with different characteristics of those found in a previous study, focused on oral-motor functions ${ }^{14}$.

Given the above, it is observed that SLH professionals are interested in increasing the use of this resource in their clinical practice, as they learn the professional norms, seek qualification in the field, and recognize the benefits the technique can offer. The clinical applicability of photobiomodulation can potentialize the gains with SLH intervention, as demonstrated in various studies $3,5,10-15,24-27$. However, some fields, with few publications, have no studies yet evidencing the effectiveness of using the resource. Currently, after the CFFa resolution was issued, the practice, studies, and research in the field are even more likely, pointing to further advances and improvements.

In this regard, this study is relevant for presenting a survey of professional profiles related to the use of this therapeutic resource. It can contribute to reflections and to the formulation and implementation of strategies to disseminate the nationwide use of the technique. Furthermore, it is important to encourage the qualification of human resources, including photobiomodulation-related content to complement the courses in SLH curricula, because of the benefits the technique can bring, as already scientifically evidenced and widely discussed in international literature, in various health professions.

\section{CONCLUSION}

Most of the Brazilian SLH therapists who participated in the research reported having information on LLL photobiomodulation and its usefulness in SLH therapy. The participants' profile regarding the use of the resource revealed that most of the professionals agree on its therapeutic use and have access to a laser device - although they do not use it yet, neither research nor publish on the theme. Also, the use of the resource in clinical practice was significantly associated with the SLH therapist's main specialization, time in the profession, access to the CFFa recommendations, and studying or obtaining the qualification to work with photobiomodulation.

\section{REFERENCES}

1. Ordahan B, Karahan AY. Role of low-level laser therapy added to facial expression exercises in patients with idiopathic facial (Bell's) palsy. Lasers Med Sci. 2017;32(4):931-6.

2. De Freitas LF, Hamblin MR. Proposed mechanisms of photobiomodulation or Low-Level Light Therapy. IEEE J. Sel. Topo. Quantum Electron. 2016;22(3):7000417.

3. El Mobadder $M$, Farhat $F$, Nammour S. Photobiomodulation Therapy in the treatment of chronic dysphagia post hormonal therapy in a breast cancer patient. Dent J (Basel). 2019;7(2):53.

4. Machado BCZ, Mazzetto MO, Da Silva MAMR, De Felício CM. Effects of oral motor exercises and laser therapy on chronic temporomandibular disorders: a randomized study with follow-up. Lasers in medical Science. 2016;31(5):945-54.

5. Batista SL, Coêlho JF, Almeida LNA, Spinelli-Pessoa L, Vasconcelos ML, Alves GAS. Oral amplitude and orofacial pain in patients with temporomandibular dysfunction submitted to lasertherapia and a miofacional orofacial therapy. Rev. bras. ciênc. saúde. 2019;23(2):85-94.

6. Conselho Federal de Fonoaudiologia [Internet]. Resolução CFFa no 541, de 15 de março de 2019 [accessed on 2020, Sep 1]; Available at: https:// www.fonoaudiologia.org.br/resolucoes/. 
7. Lizarelli RFZ. Protocolos clínicos odontológicos: uso do laser de baixa intensidade. 4 ed. São Paulo: MM Optics Ltda; 2010.

8. Anders JJ, Lanzafame RJ, Arany PR. Low-level Light/Laser therapy versus photobiomodulation therapy. Photomed Laser Surg. 2013;33(4):183-4.

9. Gomes CF, Schapochnik A. The therapeutic use of low-intensity laser (LLLT) in some diseases and its relation to the performance in speech therapy. Distúrb. Comun. 2017;29(3):570-8.

10. Vanderlei T, Bandeira RN, Canuto MSB, Alves GAS. Low-level light therapy and peripheral facial paralysis: integrating literature review. Laser therapy and Bell palsy. Distúrb Comum. 2019;31(4):557-64.

11. Zecha JA, Raber-Durlacher JE, Nair RG, Epstein JB, Elad S, Hamblin MR et al. Low-level laser therapy/photobiomodulation in the management of side effects of chemoradiation therapy in head and neck cancer: part 2: proposed applications and treatment protocols. Support Care Cancer. 2016;24(6):2793-805.

12. Lee J, Sehwan K, Jung JA, Lee MY. Applications of photobiomodulation in hearing research: from bench to clinic. Biomed. Eng. Lett. 2019;9(3):351-8.

13. Choi JE, Lee MY, Chung PS, Jung JY. A preliminary study on the efficacy and safety of low-level light therapy in the management of cochlear tinnitus: a single-blind randomized clinical trial. Int Tinnitus $\mathrm{J}$. 2019;23(1):52-7.

14. Matos AS, Berretin-Felix G, Bandeira RN, Lima JAS, Almeida LNA, Alves GAS. Laser therapy applied to orofacial motricity: perception of members of the Brazilian Orofacial Motricity Association - Abramo. Rev. CEFAC. 2018;20(1):61-8.

15. Kagan LS, Heaton JT. The effectiveness of Low-Level Light Therapy in attenuating vocal fatigue. J Voice. 2017;31(3):384.e15-384.e23.

16. Costa SAP, Florezi GP, Artes GE, Costa JR, Gallo RT, Freitas PM et al. The analgesic effect of photobiomodulation therapy $(830 \mathrm{~nm})$ on the masticatory muscles: a randomized, double-blind study. Braz. oral res. 2017;31:e107.

17. Poloni MM, Marques NP, Ribeiro Junior NV, Sperandio FF, Hanemann JAC, de Carli ML. Bell's palsy treated with photobiomodulation in an adolescent: rare case report and review of the published literature. Int $\mathrm{J}$ Paediatr Dent. 2018;28(6):658-62.
18. Ferrera MT, Hernández ZMS, Risset CL, Castro CV. Evaluación clínica y funcional de pacientes con parálisis de Bell tratados con láserClinical and functional evaluation of patients with Bell's palsy treated with laser. MEDISAN [journal on the internet]. 2015 [accessed on 2020 Sep 23];19(12):1459-65. Available at: http://scielo.sld. $\mathrm{cu} /$ scielo. php? script $=$ sci_arttext \&pid $=$ S102930192015001200004\&lng=es.

19. Cunha LO, Silva DCC, Pedra EFP, Alves VMN, Vicente LCC. Efeitos da fotobiomodulação na produção de saliva e no disparo de deglutição: relato de caso. In: Anais do XXVII Congresso Brasileiro de Fonoaudiologia. 2019 Oct; 09-12. Belo Horizonte.

20. Borges RMM, Cardoso DS, Flores BC, da Luz RD, Machado CR, Cerveira GP et al. Effects of different photobiomodulation dosimetries on temporomandibular dysfunction: a randomized, double-blind, placebo-controlled clinical trial. Lasers in Medical Science. 2018;33(9):1859-66.

21. Buchaim RL, Andreo JC, Barraviera B, Ferreira Junior RS, Buchaim DV, Rosa Junior GM et al. Effect of Low-Level Laser Therapy (LLLT) on peripheral nerve regeneration using fibrin glue derived from snake venom. Injury. 2015;46(4):655-60.

22. Susanibar F, Santos R, Marchesan I. International Orofacial Motricity Day "Tongue-tie, affected orofacial functions". Rev. CEFAC. 2017;19(1):3-6.

23. Nampo FK, Cavalheri V, Soares FS, Ramos SP, Camargo EA. Low-level phototherapy to improve exercise capacity and muscle performance: a systematic review and meta-analysis. Lasers Med Sci. 2016;31(9):1957-70.

24. El Mobadder M, Farhat F, El Mobadder W, Nammour S. Photobiomodulation Therapy in the treatment of oral mucositis, dysphagia, oral dryness, taste alteration, and burning mouth sensation due to cancer therapy: a case series. Int J Environ Res Public Health. 2019;16(22):4505.

25. Reolon LZ, RIGO L, Conto F, Cé LC. Impacto da laserterapia na qualidade de vida de pacientes oncológicos portadores de mucosite oral. Rev. odontol. UNESP. 2017;46(1):19-27. 
26. Neaser AM, Ho M, Martin P. Improved language after scalp application of Red/Near-Infrared Light Diodes: pilot study supporting a new, noninvasive treatment for chronic aphasia. Procedia Soc Behav Sci. 2012;61:138-9.

27. Alves VMN, Furlan RMMM, Motta AR. Immediate effects of photobiomodulation with low-level laser therapy on muscle performance: an integrative literature review. Rev. CEFAC. 2019;21(4):e12019. 


\section{APPENDIX: QUESTIONNAIRE USED FOR DATA COLLECTION}

\begin{tabular}{|c|c|}
\hline Question & Answer options \\
\hline Age $^{\star}$ & Open-ended answer \\
\hline State where you work* & $\begin{array}{l}\text { AC, AL, AP, AM, BA, CE, DF, ES, GO, MA, MT, MS, MG, PA, PB, } \\
\text { PR, PE, PI, RJ, RN, RS, RO, RR, SC, SP, SE, TO. }\end{array}$ \\
\hline Time working as a speech-language-hearing therapist* & $\begin{array}{l}\text { Up to } 1 \text { year } \\
\text { From } 1 \text { to } 5 \text { years } \\
\text { From } 5 \text { to } 10 \text { years } \\
\text { From } 10 \text { to } 20 \text { years } \\
21 \text { years or more } \\
\end{array}$ \\
\hline Education (highest degree) * & $\begin{array}{l}\text { Bachelor's degree } \\
\text { Specialization degree } \\
\text { Specialization student } \\
\text { Master's degree } \\
\text { Master's student } \\
\text { Doctor's degree } \\
\text { Doctoral student }\end{array}$ \\
\hline $\begin{array}{l}\text { Your main specialization is in (if you have a postgraduate degree): } \\
\text { * }\end{array}$ & $\begin{array}{l}\text { I do not have a specialization } \\
\text { AUDIOLOGY } \\
\text { LANGUAGE } \\
\text { ORAL-MOTOR FUNCTIONS } \\
\text { PUBLIC HEALTH } \\
\text { VOICE } \\
\text { DYSPHAGIA } \\
\text { EDUCATIONAL SLH PATHOLOGY } \\
\text { GERONTOLOGY } \\
\text { NEUROFUNCTIONAL SLH THERAPY } \\
\text { OCCUPATIONAL SLH THERAPY } \\
\text { NEUROPSYCHOLOGY } \\
\text { FLUENCY }\end{array}$ \\
\hline Field(s) of work * & $\begin{array}{l}\text { AUDIOLOGY } \\
\text { LANGUAGE } \\
\text { ORAL-MOTOR FUNCTIONS } \\
\text { PUBLIC HEALTH } \\
\text { VOICE } \\
\text { DYSPHAGIA } \\
\text { EDUCATIONAL SLH PATHOLOGY } \\
\text { GERONTOLOGY } \\
\text { NEUROFUNCTIONAL SLH THERAPY } \\
\text { OCCUPATIONAL SLH THERAPY } \\
\text { NEUROPSYCHOLOGY } \\
\text { FLUENCY }\end{array}$ \\
\hline Work setting(s) * & \begin{tabular}{|l} 
Clinic \\
Classroom \\
Home Care \\
Hospital \\
School \\
Other:
\end{tabular} \\
\hline
\end{tabular}




\begin{tabular}{|c|c|}
\hline Do you teach? (Only for professors) * & \begin{tabular}{|l|} 
Undergraduate \\
Postgraduation \\
Both \\
Not applicable \\
\end{tabular} \\
\hline Teaches in Postgraduation (Only for professors) * & $\begin{array}{l}\text { Specialization } \\
\text { Master's or doctor's program } \\
\text { No } \\
\text { Both } \\
\text { Not applicable } \\
\end{array}$ \\
\hline Are you a professor whose content includes laser? * & \begin{tabular}{|l|} 
Yes \\
No \\
Not applicable \\
\end{tabular} \\
\hline $\begin{array}{l}\text { Do you know what LASER THERAPY/PHOTOBIOMODULATION } \\
\text { is? * }\end{array}$ & $\begin{array}{l}\text { Yes } \\
\text { No }\end{array}$ \\
\hline $\begin{array}{l}\text { Do you know the use of laser in speech-language-hearing } \\
\text { therapy? * }\end{array}$ & $\begin{array}{l}\text { Yes } \\
\text { No }\end{array}$ \\
\hline $\begin{array}{l}\text { Have you ever researched or published anything in the field of } \\
\text { laser therapy? * }\end{array}$ & $\begin{array}{l}\text { Yes } \\
\text { No }\end{array}$ \\
\hline If so, what was the field of research or publication? * & $\begin{array}{l}\text { I did not research/publish } \\
\text { AUDIOLOGY } \\
\text { LANGUAGE } \\
\text { ORAL-MOTOR FUNCTIONS } \\
\text { PUBLIC HEALTH } \\
\text { VOICE } \\
\text { DYSPHAGIA } \\
\text { EDUCATIONAL SLH PATHOLOGY } \\
\text { GERONTOLOGY } \\
\text { NEUROFUNCTIONAL SLH THERAPY } \\
\text { OCCUPATIONAL SLH THERAPY } \\
\text { NEUROPSYCHOLOGY } \\
\text { FLUENCY } \\
\end{array}$ \\
\hline $\begin{array}{l}\text { Have you had access to the CFFa recommendations on the use of } \\
\text { laser by speech-language-hearing therapists? }{ }^{*}\end{array}$ & $\begin{array}{l}\text { Yes } \\
\text { No }\end{array}$ \\
\hline $\begin{array}{l}\text { Have you taken any studies/qualifications on laser therapy/ } \\
\text { photobiomodulation in SLH therapy or health care? * }\end{array}$ & $\begin{array}{l}\text { Yes } \\
\text { No }\end{array}$ \\
\hline Course load taken in Laser therapy: * & Open-ended answer \\
\hline $\begin{array}{l}\text { Was laser therapy included at any moment during your } \\
\text { undergraduate studies? }{ }^{*}\end{array}$ & $\begin{array}{l}\text { Yes } \\
\text { No }\end{array}$ \\
\hline $\begin{array}{l}\text { Was laser therapy included at any moment during your } \\
\text { postgraduate studies? * }\end{array}$ & $\begin{array}{l}\text { Yes } \\
\text { No } \\
\text { I have not studied in postgraduation }\end{array}$ \\
\hline $\begin{array}{l}\text { Do you have/have you had access to any bibliography related to } \\
\text { the field of laser therapy in SLH therapy or health care * }\end{array}$ & $\begin{array}{l}\text { Yes } \\
\text { No }\end{array}$ \\
\hline Do you have access to a low-level laser device? * & $\begin{array}{l}\text { Yes, I have a private device } \\
\text { Yes, I rented/borrowed one } \\
\text { Yes, there is one at the university/laboratory } \\
\text { I do not have access to it } \\
\text { Other: }\end{array}$ \\
\hline Do you normally use the laser in your clinical practice? * & $\begin{array}{l}\text { Yes } \\
\text { No }\end{array}$ \\
\hline
\end{tabular}




\begin{tabular}{|c|c|}
\hline $\begin{array}{l}\text { On a scale from } 0 \text { to } 5 \text {, in which } 0 \text { means "never" and } 5 \text { means } \\
\text { "always", how often do you use the laser in your routine? ** }\end{array}$ & $\begin{array}{l}0 \\
1 \\
2 \\
3 \\
4 \\
5\end{array}$ \\
\hline $\begin{array}{l}\text { In what cases do you most often use the laser? List three cases } \\
\text { at most. ** }\end{array}$ & Open-ended answer \\
\hline $\begin{array}{l}\text { On a scale from } 0 \text { to } 5 \text {, in which } 0 \text { means "nothing" and } 5 \text { means } \\
\text { "much", to what extent does low-level laser result in greater } \\
\text { patient adherence? }{ }^{\star *}\end{array}$ & $\begin{array}{l}0 \\
1 \\
2 \\
3 \\
4 \\
5\end{array}$ \\
\hline $\begin{array}{l}\text { How long have you had your qualification in the field of laser } \\
\text { therapy? (in years) ** }\end{array}$ & Open-ended answer \\
\hline $\begin{array}{l}\text { How long have you been using low-level laser in clinical practice? } \\
\star \star\end{array}$ & Open-ended answer \\
\hline At what moment of the therapy do you use the laser? ** & $\begin{array}{l}\text { Beginning } \\
\text { Middle } \\
\text { End }\end{array}$ \\
\hline $\begin{array}{l}\text { What photobiomodulation/laser therapeutic effect do you most } \\
\text { often use in clinical routine? }{ }^{\star \star}\end{array}$ & Open-ended answer \\
\hline $\begin{array}{l}\text { Of the clinical situations below, in what indications for laser } \\
\text { therapy do/would you intervene? (Only for oral-motor function } \\
\text { specialists) * }\end{array}$ & $\begin{array}{l}\text { Facial palsy } \\
\text { TMD } \\
\text { Both } \\
\text { If you are not a specialist in oral-motor functions, this is not } \\
\text { applicable } \\
\text { Other: }\end{array}$ \\
\hline $\begin{array}{l}\text { Do you agree that the speech-language-hearing therapist } \\
\text { specialized in oral-motor functions must use laser therapy? } \\
\text { (Answer only if you are an oral-motor function specialist) * }\end{array}$ & \begin{tabular}{|l|} 
Yes \\
No \\
Not applicable
\end{tabular} \\
\hline Do you know the biosafety rules to use the laser? * & $\begin{array}{l}\text { Yes } \\
\text { No }\end{array}$ \\
\hline $\begin{array}{l}\text { Do you agree that a speech-language-hearing therapist can use } \\
\text { the low-level laser as a therapeutic resource? * }\end{array}$ & \begin{tabular}{|l|} 
Yes \\
No
\end{tabular} \\
\hline $\begin{array}{l}\text { Please, include comments you find appropriate to our survey } \\
\text { or make any observation you consider important in the } \\
\text { questionnaire: * }\end{array}$ & Open-ended answer \\
\hline
\end{tabular}

Caption: * required answer; ** answer applies only to professionals who use the resource in clinical practice; SLH: speech-language-hearing; CFFa: Federal SpeechLanguage-Hearing Council. 